\title{
EFFECTS OF EARLY NUTRITIONAL AND ENVIRONMENTAL CONDITIONS ON LATER RUNWAY TEST BEHAVIOR IN RATS ${ }^{1}$
}

\author{
TOSHIAKI TACHIB.ANA ${ }^{2}$ \\ Institute for Developmental Research, Aichi Prefectural Colon:
}

\begin{abstract}
The effects of low-protein diet and environmental enrichment in early age were examined at maturity. New-born rats were nursed by mothers in either normal or low-protein dietary condition. After weaning, they were reared for four weeks in one of three environmental conditions; standard, enriched, and isolated. After additional four weeks of standard rearing, they were tested in a runway. There was an interaction between the nutritional and environmental conditions: A clear difference was found between the low-protein group and the normal group reared in the enriched environment, but not between those reared in the other environments. It is important to use more than one environmental conditions in nutritional experiments.
\end{abstract}

A number of studies have been reported the effects of early malnutrition on open field behavior in rats (see the reviews, e.g., Levine \& Wiener, 1976). Open field behavior can be tested under two different procedures, that is, "free" exploration procedure which allows retreat from the test field to a "safe" place and "forced" exploration procedure which does not allow the retreat. The method employed in previous studies was a test under the "forced" exploratory situation. However, some pointed out that ambulation under the "forced" situation is not a unidimensional trait (e.g., Denenberg, 1969; Fujita, 1975). Whimbey and Denenberg (1967) showed that high activity indicates high emotionality in the earlier stage of exposure to a field, while high activity in the later stage is indicative of low emotionality. It is virtually impossible to distinguish the two high activities for every animal. Thus, under the "forced" situation, the open field ambulation is calcu-

1 This research was supported in part by a Grant in Aid for Scientific Researches, Ministry of Education.

2 Request for reprints should be sent to Toshiaki Tachibana, Institute for Developmental Research, Aichi Prefectural Colony, Kamiya-cho, Kasugai, Aichi, 480-03 Japan. lated, which in itself contains two opposite trends of behavior. This problem engendered by the "forced" exploration procedure can be avoided by the use of the "free" exploration procedure.

In addition, only one environmental condition has been used to find out the nutritional effects in most studies. Fraňková (1968) was the first to use two environmental conditions and showed that an interaction exists between early nutrition and early environment in open field behavior. Though some studies (Fraňková, 1972; Levitsky \& Barnes, 1972) reported a malnutritional effects on open field behavior in two or three levels of environment, such investigation are few, and the results were not consistent each other.

Therefore, the purpose of the present study was to examine the effects of early malnutrition under three levels of environmental condition, by employing a runway test (Fujita, 1975 ) as the "free" exploration procedure.

\section{METHOD}

\section{Treatment of Animals}

The subjects were the offspring of 12 SpragueDawley mother rats. About 48 hrs after the birth, litters were reduced to eight pups, with 
the number of males maximized. The lactating mothers were then divided into two groups. One half of each litter was crossfostered between the two mother groups, in order to counterbalance the possible genetic factors. The litters were cross-fostered only if they were born on the same day. The two mother groups were then assigned to (1) low protein diet group (LP), containing $11.5 \%$ crude protein and (2) optimum protein diet group (OP), containing 27\% crude protein, respectively. The $\operatorname{diet}^{3}$ was supplied by Oriental Yeast Inc. (Tokyo). Food and water were available to the both groups at all times.

Each mother and litter were housed in a plastic standard laboratory cage until weaning. After weaning at $26 \pm 1$ days of age, each group was further divided into three subgroups equated for the mean body weights among the subgroups; standard, enriched and isolated environment group. After weaning all the animals were fed the optimum protein diet at libitum. The animals of standard environment group (SE) were housed in groups of three to four in a standard laboratory cage $(30 \times 36 \times 8 \mathrm{~cm})$. The animals of enriched environment group (EE) were allowed to play in a group of 10 to 11 , in a large wooden box $(45 \times 65 \times 60 \mathrm{~cm})$ containing many manipulative objects, including wooden blocks, balls, ladders, etc., for 4 hrs a day. The remaining condition was the same as for the standard environment group. The animals of isolated environment group (IE) were housed in individual cage $(25 \times 18 \times 20 \mathrm{~cm})$ with a tray bottom. The back, sides and top of the cage were covered with a metal hood. A food hopper and water bottle were attached to the outside of the wire mesh front door. The cages were made to face a wall. Thus, the rats could not see or touch other rats. The animals were placed in these environ-

3 Major components and caloric values (LP; OP) were as follows $(\mathrm{g} / 100 \mathrm{~g}$ of diet): moisture $(8.0 ; 7.0)$, crude protein $(11.5 ; 27.8)$, crude fat $(3.0 ; 5.5)$, crude ash $(4.2 ; 8.0)$, crude fiber $(1.7$; $4.0)$, nitrogen free extract $(71.6 ; 47.7)$, kcal (359.4; $351.5)$. mental conditions for four weeks. Thereafter, all were given the same environmental condition as the standard environmental condition for four weeks.

Only males were used as the subjects. Animals judged to be unheal thy were eliminated for the study. The final number of animals in each group was as follows: LP-SE $(n=8)$, LP-EE $(n=10)$, LP-IE $(n=8)$, OP-SE $(n=9)$, OP-EE $(n=10)$, OP-IE $(n=8)$.

\section{Runway Test}

The runway test was begun for the half of the animals from each group at eight weeks of age, and at nine weeks of age for the remainder of the animals from each group. The apparatus was essentially the same as that developed by Fujita (1975). The $150 \times 20 \times$ $45 \mathrm{~cm}$ runway was marked off into six sections, with a door located at the end of the first section. The first section was covered with an opaque top, and used as the start compartment. The plywood floor and walls were painted black. At the start of the trial, each animal was placed individually in the start compartment. After $1 \mathrm{~min}$ the door was removed and the animal was permitted $5 \mathrm{~min}$ of free exploration in the field. The start compartment door was always open permitting the animal to retreat from the open section at will. The apparatus was placed on the floor of a laboratory, directly under flourecent room lights. A ventilator provided a fairly constant mask noise. The animals received one trial daily for eight consecutive days. The latency to emerge from the start compartment and the number of sections entered with all four feet were recorded manually. If the animals did not emerge from the start compartment, they were assigned a score of $300 \mathrm{sec}$.

\section{Results}

\section{Body Weight}

The mean body weights of animals at weaning and just before the runway test are given in Table 1. A $2 \times 3$ unweighted means analysis of variance indicated that the signif- 
Table 1

Mean (and standard deviation) of body weight (in gram) for cach group

\begin{tabular}{ccccccc}
\hline Group & LP-SE & LP-EE & LP.IE & OP-SE & OP-EE & OP-IE \\
\hline Mean of body weight & & & & & & \\
At weaning & 28.9 & 30.4 & 30.8 & 68.1 & 68.6 & 67.0 \\
\multirow{2}{*}{ Before runway test } & $(1.8)$ & $(3.2)$ & $(3.2)$ & $(3.6)$ & $(6.1)$ & $(3.6)$ \\
& 283.9 & 272.5 & 299.3 & 352.7 & 339.4 & 323.8 \\
& $(47.3)$ & $(51.9)$ & $(49.5)$ & $(36.6)$ & $(24.8)$ & $(21.4)$
\end{tabular}

cant main effect was the only nutritional condition for weaning day, $F=40.70, d f=1 / 47$, $p<.01$, and for the previous day of runway test, $F=20.34, d f=1 / 47, p<.01$.

\section{Rumeay Test}

Before statistical analysis were conducted a $\log (x+1)$ transformation was made on the runway test score, which was constituted by the number of squares entered with four feet, and the start latency score, which was the latency to emerge from the start compartment. The runway test score and the start latency score for each group are presented in Fig. 1.
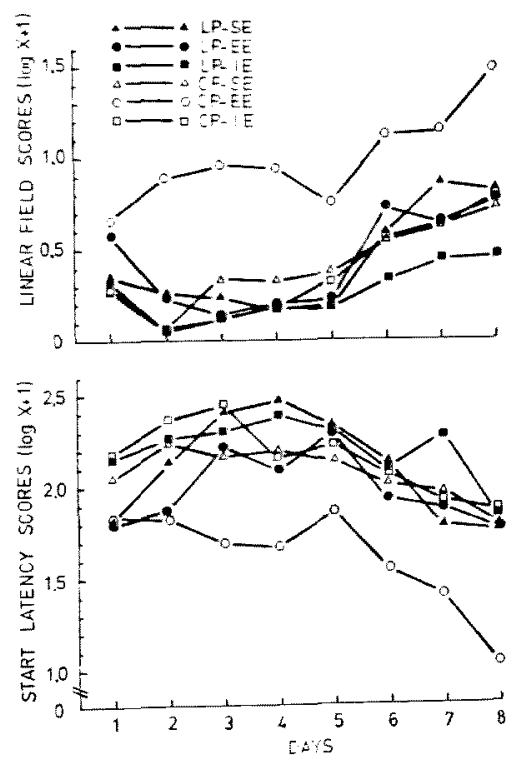

Fig. 1. Mean runway score (upper panel) and mean start latency (lower panel) for each group as a function of days. LP: low protein, OP: optimal protein, SE: standard environment, EE: enriched environment, IE: isolated environment.
Each measure was analyzed by a $2 \times 3 \times 8$ unweighted means analysis of variance, with one repeated measure. The factors were nutritional condition, environmental condition, and trial day. In the runway test score, the main effects of the three independent variables were significant $(F=6.58, d f=1 / 47$, $p<.05 ; F=8.63, d f=2 / 47, p<.01 ; F=21.50$, $d f=7 / 329, p<.01$, for nutritional condition, environmental condition, and trial day, respectively). In addition, nutritional condition $x$ environmental condition interaction was significant $(F=5.88, d f=2 / 47, p<.01)$, but not for other interactions $\left(F_{\mathrm{S}}<1\right)$. Therefore, a simple main effect was calculated. There was a significant simple main effect of nutritional condition at EE level $(F=15.38, d f=1 / 47, p<$ $.01)$, but not at SE and IE level $\left(F_{\mathrm{S}}<1\right)$. For the start latency score, the main effects of environmental condition and trial day were significant $(F=4.99, d f=2 / 47, p<.05 ; \quad F=$ $10.00, d f=7 / 329, p<.01$, respectively), but not for nutritional condition $(F=2.14, d f=1 / 47$, $p>.05)$ and all interactions.

\section{Discussion}

There was a clear difference in the runway test score between the two nutritional groups at $\mathrm{EE}$ level, but not at $\mathrm{SE}$ level and IE level. The start latency score showed a tendency similar to the runway test score. One possible interpretation of this difference is that the 8-day test period was not long enough to ascertain the group difference, because all groups except OP-EE group remained at a low level of activity. However, this possibility, if any, does not weaken the evidence that environmental enrichment effects on run- 
way test behavior were greater in OP groups than LP groups.

There have been conflicting results in the study of malnourishment effects on open field behavior. Some studies have found a difference in open field behavior between malnourished rats and normal rats (e.g., Simonson, Stephan, Hanson, \& Chow, 1971), while others found none (Ottinger \& Tanabe, 1968). It must be noted that in the present study an interaction of nutritional condition $\times$ environmental condition was obtained. This means that nutritional effects depend on environmental conditions. Thus, in addition to the difference in the test procedure, the difference in environmental conditions may be a possible source for the conflicting results.

Levitsky and Barnes (1972) showed that malnutritional effects were exaggerated by environmental isolation and depressed by environmental stimulation in open field behavior. This type of interaction seems to offer some hope for rehabilitation. However, the type of interaction in the present study differs from that of Levitsky and Barnes. In the study of Im, Barnes, and Levitsky (1976), an interaction similar to that of the present study is noted among the control diet groups, in which the environmental effects on brain nitrogen concentration were evident, but this was not true among the malnutrition groups. Therefore, it is also important to note the type of interaction shown in the present study. The reason for the different type of interaction is not clear. However, these findings illustrate the importance of using more than one environmental condition. If only $\mathrm{SE}$ groups were used in the present study as in most, it might have been concluded that there is no malnutritional effect on runway test behavior. Such a conclusion is clearly premature. Thus, the general conclusion reached by previous studies in which only one environmental condition was employed, must be qualified and restricted.

\section{REFERENCES}

Denenberg, V. H. 1969 Open-field behavior in the rat: What does it mean? Annals of the Now Tork Academy of Sciences, 159, 852-859.

FrañKová, S. 1968 Nutritional and psychological factors in the development of spontaneous behavior in the rat. In N. S. Schrimshaw \& J. E. Gordon (Eds.), Malnutrition, learning and behavior. Cambridge: M.I.T. Press, Pp. 312-322.

Frañkova, S. 1972 Effect of early dietary and sensoric reduction on behaviour of adult rats. Activitas Nervosa Superior (Praha), 14, 1-7.

FujirA, O. 1975 Behavior-genetic analysis of responses in runway test as measures of emotional reactivity in rats: I. Phenotypic variations and heritability estimates based on offspring-parents regressions. The fapanese fournal of Psychology, 46, 281-292. (In Japanese with English summary)

Im, H. S., Barnes, R. H., \& Levitsky, D. A. 1976 Effects of early protein-energy malnutrition and environmental changes on choliesterase activity of brain and adrenal glands of rats. Journal of Nutrition, 106, 342-349.

Levine, S., \& Wiener, S. G. 1976 Malnutrition and early environmental experience: Possible interactive effects on later behavior. In R. N. Walsh \& W.T. Greenough (Eds.), Environments as therapy for brain dysfunction. New York: Plenum Press. Pp. 51-70.

Levitsky, D. A., \& Barnes, R. H. 1972 Nutritional and environmental interactions in the behavioral development of the rat: Long-term effects. Science, 176, 68-71.

Ottinger, D. R., \& Tanabe, G. 1968 Maternal food restriction: Effects on offspring behavior and development. Developmental Psychobiology, 2, 7-9.

Simonson, M., Stephan, J. K., Hanson, H. M., \& Chow, B. F. 1971 Open field studies in offspring of underfed mother rats. Fournal of Nutrition, 101, 331-336.

Whimbey, A. E., \& Denenberg, V.H. 1967 Two independent behavioral dimensions in open-field performance. Fournal of Comparative and Physiological Psychology, 63, 500-504.

(Received Aug. 14, 1978) 